\title{
Disclosing Strategies and Business Models in the Integrated Report*
}

\author{
Elisa Truant ${ }^{* *}$, Francesca Culasso ${ }^{* * *}$, Daniela Argento ${ }^{* * * *}$
}

\begin{abstract}
The purpose of this paper is to explore the extent to which strategies and business models (BMs) are disclosed in Integrated Reports (IRs). In addition, this paper seeks to understand the reasons for the changes in such disclosures over time. A longitudinal case study focusing on Terna, an Italian listed public utility operating in the electricity sector, is presented. Multiple methods of data collection and analysis were adopted. A content analysis based on the framework of Sukhari and De Villiers (2018) was performed on Terna's IRs from 2011 to 2017. Interviews were conducted with several managers to integrate the data stemming from the content analysis. The paper opens up the 'black box' of corporate strategy disclosures, showing how they can evolve over time. The findings reveal a resistance to fully communicating sensitive corporate information related to strategic goals and their implementation.
\end{abstract}

Keywords: Integrated Reporting; Strategy; Business Model; Disclosure; Content Analysis; Global Markets

\section{Globalisation and Stakeholders' Interests}

Over the last thirty years, globalisation, together with recommendations of supranational organisations and stakeholders' interests, have stimulated the development and integration of sustainable practices within organisations (Brondoni, 2003, 2014; Brondoni \& Bosetti, 2018; Mosca \& Civera, 2017). Integrating sustainability into business strategies and operations entails interaction with a wide range of stakeholders (Brondoni \& Bosetti, 2018).

Contemporary organisations are increasingly called to demonstrate, through their external communication processes, that they have a sustainable business model (BM) (Cho \& Patten, 2007; Schaltegger et al., 2012). A BM should be able to create value for all stakeholders in the short term and especially in the medium to long term, lending legitimacy to organisational activities and outcomes (Epstein \& Buhovac, 2014; Epstein \& Roy, 2001).

Corporate disclosures currently consist of both traditional financial information and non-financial information (De Villiers et al., 2014; Stent \& Dowler, 2015). The

\footnotetext{
${ }^{*}$ The Authors: Truant, E. $\S \S 4,5$, Culasso, F. $\S \S 1,2$, Argento, D. $\S \S 3,6$

** Assistant Professor of Business Administration, University of Turin (elisa.truant@unito.it)

${ }^{* * *}$ Full Professor of Business Administration, University of Turin (francesca.culasso@unito.it)

${ }^{* * * *}$ Associate Professor of Management Accounting, Kristianstad University (daniela.argento@hkr.se)
} 
latter has gained relevance because it has been argued that non-financial information is able to measure critical success factors, which are the true determinants of an organisation's value over time (De Villiers et al., 2014). Nonfinancial information enhances a culture oriented towards sustainable development and is generally produced by corporate information systems aimed at supporting managerial strategic and operative decision-making processes (Cantino \& Cortese, 2017). Since the mid-1990s, academics and practitioners have recommended the use of both financial and non-financial performance indicators in multidimensional performance measurement/management systems (Epstein \& Manzoni, 1997; Lev, 2001); one of the most popular of these systems is the Balanced Scorecard (BSC) (Kaplan \& Norton, 1992, 1996).

Organisations have therefore undergone an epochal change, which requires stronger integration between financial accounting and management accounting. Zambon (2011) claimed that managerialisation of financial reporting is occurring in that the future of financial accounting appears to be strictly linked to the development of management accounting techniques and practices.

One tool that can enhance the integration between financial and non-financial information is the Integrated Report (IR). According to the International Integrated Reporting Council (IIRC) framework (IIRC, 2013a), the IR is 'a concise communication about how an organisation's strategy, governance, performance and prospects, in the context of its external environment, lead to the creation of value over the short, medium and long term' (IIRC, 2013a, p. 7). It follows that integrated reporting entails the disclosure of an organisation's strategy and BM (Sukhari \& De Villiers, 2018; De Villiers et al., 2014) together with social, environmental, financial and governance disclosures.

However, an integrated vision of sustainability dimensions requires a redefinition of BMs and responsibilities that involves all business functions (Mosca \& Civera, 2017). The IR enables organisations to inform all the stakeholders in a clear, transparent and comparable way about the goals established, the results achieved and the different responsibilities held, from a sustainability perspective (Salvioni \& Bosetti, 2014).

Although research on integrated reporting has proliferated in the academic literature (Argento et al., 2019; De Villiers et al., 2016; De Villiers et al., 2017; Dumay et al., 2016; Stubbs \& Higgings, 2014), gaps remain to be filled. De Villiers et al. (2014) argued that the processes of integrating different types of information to produce the IR are not well understood. Cheng et al. (2014) emphasised the difficulties in satisfying the information needs of all stakeholders, given that providers of financial capital are prioritised over other stakeholders. Moreover, Sukhari and De Villiers (2018) stated that there has been a lack of studies on how organisations disclose the relationship between their BM and strategy, and studies examining the changes in these disclosures over time. Melloni et al. (2016) go farther and cast some doubt on the role of the IR in improving reporting on the BM. In addition, Stubbs and Higgings (2014) underscored that the implementation dynamics are still unclear because of the lack of understanding regarding whether integrated reporting drives organisational changes. These authors have called for research at the level of single organisations (Stubbs \& Higgings, 2014) to identify the elements that enable or hinder the implementation of integrated reporting over 
time.

In attempting to fill these gaps in the literature, the purpose of this paper is to explore the extent to which strategies and BMs are disclosed in the IRs. In addition, this paper seeks to understand the reasons for the changes in such disclosures over time.

Through a content analysis of one organisation's IRs from 2011 to 2017, this paper examines how the disclosures of strategy and BM changed over time. The organisation in focus is Terna, an Italian public utility operating in the electricity sector and listed on the Italian stock exchange which has voluntarily adopted integrated reporting. The research question addressed is: To what extent can the strategy and BM be disclosed in the IR?

By drawing upon the notions of BMs (Zott et al., 2011) and their links with the management accounting literature (Cinquini \& Tenucci, 2011), this paper unveils how and why the voluntary preparation of IRs does not necessarily entail a complete disclosure of the BM and related strategies.

\section{Theoretical Framework}

The adoption of integrated reporting, even on a voluntary basis, represents a relevant effort for an organisation and indicates a willingness to integrate sustainability and governance information into a unique disclosure process and tool (De Villiers et al., 2014; Stent \& Dowler, 2015). Despite the increase in the volume of disclosures since the adoption of integrated reporting (Haji \& Anifowose, 2016), it has been observed that, in many cases, such disclosures are rather generic and not particularly focused on strategic information (Du Toit et al., 2017; Haji \& Anifowose, 2016).

The preparation of an IR assumes that strategic information concerning the organisation should first be internally discussed and then disclosed to external stakeholders (Argento et al., 2019). The process of internally discussing and then disclosing relevant information is very delicate, considering that an IR should communicate the organisation's strategy and BM, measuring the BM's key success factors, that is, how an organisation proposes, creates, delivers and captures value not only in the short term but also, and especially, over the long term (Salvioni \& Bosetti, 2014; Stubbs \& Higgings, 2014). Such an approach requires collaboration among different units or teams within the organisation (Salvioni \& Bosetti, 2014) in order to enhance a holistic representation of the organisation's goals, activities and performances.

The term BM refers to the attempt to communicate, in more or less detail, the way in which an organisation conducts its business, simplifying the different forms of complexity present in the business itself. However, although the current debate on the BM concept is extensive and lively (Zott et al., 2011), it is not possible to identify a unique definition of this concept due to the different streams of literature contributing to the topic itself (Zott et al., 2011; Sukhari \& De Villiers, 2018).

Chesbrough and Rosenbloom (2002) declared that the origin of the BM concept can be found in the work of Chandler entitled 'Strategy and Structure' (1962), in which the author explained the strategy concept as the process through which an 
organisation identifies its own long-term goals and how to attain them. A strategy implies the formulation of a plan of action that refers to the intentions of the organisation, considering its products/services and customers, the countries in which it operates and its activities and resource allocations (Grant, 2016). Strategy is strictly linked with the BM, and an organisation's BM cannot be executed without a strategy (Teece, 2010).

Amit and Zott (2001) defined the BM as a template depicting 'the content, structure, and governance of transactions designed so as to create value through the exploitation of business opportunities' (Amit \& Zott, 2001, p. 511). Since transactions connect activities between different organisations, the definition of BM has expanded to also refer to the "value obtained through the collaboration between a focal organisation and its partners' (Amit \& Zott, 2010, p. 216). In Chesbrough and Rosenbloom (2002), the BM became the 'heuristic logic' that links technical potential with the realisation of the economic value of an organisation. The key elements of a BM have been identified in key activities, partner networks, key resources, cost structures, revenue flows, value propositions, client segments and client relationships (Osterwalder, 2004). Focusing on the BM features identified by Osterwalder and Pigneur (2010), it is possible to interpret the BM as a construct whereby an organisation creates, delivers and captures value for itself, its partners and its customers. Following this approach, the BM assumed importance as a new additional unit of analysis (Zott et al., 2011). The BM is a 'systems concept' that goes beyond organisational boundaries and embraces the different actors present in a specific context (Melloni et al., 2016; Milne, 2007); therefore, it is even more crucial to consider the $\mathrm{BM}$ as a construct involving a focal organisation and other interested organisations (Zott et al., 2011). Collaboration among these organisations can contribute to achieving the shared goal of value creation.

Lambert (2008) showed how the BM of an organisation can be useful for three different types of users: i) external users, such as business consultants, analysts, members of the legal profession, researchers and investors; ii) managers and other decision makers; and iii) information systems developers.

Nielsen and Bukh (2011) considered the BM the 'foundation of the company's strategy' and proposed a framework through which adequate information can be provided to stakeholders, especially external stakeholders. Additionally, the IIRC formed a Technical Collaboration Group to define the term BM and to provide guidance for the disclosure of an organisation's BM and strategies (IIRC, 2013b).

In essence, the BM describes how the organisation operates and how it creates value for its stakeholders, while a strategy refers to the choice of BM through which the organisation will be able to compete (Casadesus-Masanell \& Ricart, 2010). The BM, according to a narrow perspective, should explain 'the combination of tangible and intangible resources needed for the creation of value' (Cinquini \& Tenucci, 2011, p. 48).

Combining the various definitions provided above, it seems clear that the BM should allow both managers and external stakeholders to perceive the organisation with a deep level of detail, from the strategic level, passing through the operational level and arriving at the economic level. In particular, 'at the strategic level, it is possible to explain the value proposed to the customer and the network of partnership and alliances that the organisation has; at the operational level, it allows 
[us] to outline the internal processes, resources and competences that enable the organisation to offer value; at the economic level, finally, the BM helps to highlight the mechanism that allows the generation of revenues' (Cinquini \& Tenucci, 2011, p. 51).

It is therefore evident that the BM enables the creation of a balanced set of indicators, both financial and non-financial, and that management accounting can play a very relevant role in providing information to describe the $\mathrm{BM}$ of an organisation. In particular, the contribution of management accounting consists of the ability to identify the most appropriate financial and non-financial indicators, quantifying both past and future performances and reflecting the critical success factors of the BM of the organisation in a cause-and-effect relationship (Cinquini \& Tenucci, 2011). In this regard, the BSC, identifying the key success factors and the related key performance indicators, 'strongly complements the concept of BM, in the sense that it provides an approach to search for the cause-and-effect relationship between strategic objectives shared among different perspectives of business' (Cinquini \& Tenucci, 2011, p. 53).

The discussion above shows the potential value of communicating the relationship among the organisation's BM and its strategy, governance and performance to investors and other stakeholders (Topazio, 2013) by publishing an IR. However, organisations' desires to protect their competitive advantages could clash with the original intent of the IR (as intended by the IIRC - IIRC, 2013a). It is argued that many organisations mainly implement integrated reporting to satisfy the information needs of institutional investors and market analysts (Cheng et al., 2014). Nevertheless, the aim of gaining a better reputation and image does not always go hand in hand with the full communication of the BM (Sukhari \& De Villiers, 2018).

Having this theoretical framework in mind, the next section describes the research method adopted in the study.

\section{Research Method}

A case study methodology (Yin, 1994) with a longitudinal perspective was adopted to explore how the BM and strategy disclosures in the IRs of Terna S.p.A. have changed over time. Terna represents a relevant case study in the field of integrated reporting because it was one of the first Italian listed companies to enter the Business Network Pilot Program of the IIRC.

$\square$ Terna S.p.A. (henceforth Terna) is an Italian public utility headquartered in Rome (Italy) and listed on the Italian stock exchange since 2004. Terna's main business is the transmission and dispatching of electricity in Italy. The transmission and dispatching of electricity are regulated activities with remuneration based on a tariff established by the Italian Regulatory Authority for Electricity, Gas and Water (AEEGSI). Terna is the largest independent electricity transmission system operator in Europe and a key player worldwide in terms of 
kilometres of electricity lines managed (Terna, 2018). Furthermore, Terna plays a leading role in important European electricity industry associations (Terna web page). Additionally, since 2014, Terna has reached the top positions of the prestigious Dow Jones Sustainability World Index, which evaluates more than 2,000 companies worldwide. Terna has also been rewarded by the Swiss sustainability rating RobecoSAM Group, in both the world and Europe indices (RobecoSAM, 2018).

The annual results of Terna (2011-2017) show very good financial and sustainability performances. It was recognized by the DJ Sustainability Index as an industry leader and as one of the world's most sustainable companies (RobecoSAM, 2018). These results confirm the significance of the selected case study (Eisenhardt \& Graebner, 2007).

Multiple data collection methods were used to prepare the case study. This paper is part of a larger research project about the implementation of integrated reporting (see Argento et al., 2019), which specifically focuses on disclosures of strategy and BM. Therefore, for the specific purpose of this paper, a content analysis was executed because of its usefulness in achieving a deeper understanding of corporate disclosure content and practices (Beattie et al., 2004; Guthrie et al., 2004; Unerman, 2000; Weber, 1990).

The IRs from 2011 to 2017 were downloaded from Terna's website, and the content analysis was executed using the framework proposed by Sukhari and De Villiers (2018). This framework consists of a checklist including 14 items for the strategy disclosures and 23 items for the BM disclosures. A Microsoft Excel file was created to report the results of the checklist for each of the eight examined IRs. Each item was codified as thoroughly disclosed $(\boldsymbol{\checkmark})$, not disclosed $(\mathrm{X})$, or only partially disclosed or fragmented (§).

In addition, the connection between $\mathrm{BM}$ and strategy was investigated by analysing whether the strategic goals disclosed in the IR are linked to the BM of the company, and a percentage was calculated.

The IRs were read and analysed by one of the three authors of this paper to overcome inter-coder reliability problems. Intra-coder reliability was ensured by the relatively small number of IRs to be analysed (i.e., 8) and the existence of a wellstructured checklist (Bryman \& Bell, 2011). The table of contents of each IR was preliminarily used to identify the sections that were relevant for the research. However, in some years, the BM and the strategic objectives were not clearly identified in the IR; in such situations, the IR was deeply scrutinised to find synonyms or expressions (e.g., company's target, strategic initiatives, business performance models, the way in which the company conducts business) that could lead to such topics.

The results were also scored and tabulated to enhance a comparison among different years and comparison with the information collected through interviews. Thirteen in-depth interviews were conducted with the managers of Terna involved in integrated reporting and in the strategic planning process. Specifically, the following interviews were conducted: three with the Corporate Social 
Responsibility (CSR) manager, two with the past (until October 2016) and one with the current (as of January 2019) CFO. Two interviews were conducted with the past (until February 2018) and one with the current (as of the January 2019) Strategic Planning manager, two with the Human Resources manager, and two with the Investor Relations manager. To address the contextual validity issues of this study (Ryan et al., 2002), the respondents were selected because of their involvement in the implementation of integrated reporting and in the Strategic Planning area.

The interviews were conducted from July 2016 to January 2019 to depict the changes in IR disclosures over time. The interviews were semi-structured and lasted between 22 and 122 minutes. Five interviews were conducted face-to-face, three via telephone and five via Skype.

Respondents were asked questions about the implementation process and the content of the IR, with a specific focus on strategic planning and control issues and with the aim of depicting the changes in Terna's integrated reporting practices, and disclosures of strategy and BM. To interpret the past, retrospective interview methods (Wolfram Cox \& Hassard, 2007) were used. Additionally, the interviews were recorded and transcribed to increase procedural reliability (Ryan et al., 2002). Then, each interview transcript was analysed, and the respondents' statements were compared to identify inconsistencies or distortions.

Additional information was also derived from internal documents (internal newspapers and other documents available on the intranet) made available during a visit to the case organisation.

Finally, the results were discussed and interpreted by the three authors of this paper by iteration with the theoretical framework presented earlier. Interpretations were made by considering the limitations inherent to the single-case study approach. Although generalisations are not possible, the analysis has provided interesting findings about the possibilities to integrate strategy and BM disclosures in the IR.

\section{Strategy, BM and IR: Possible Integration?}

To deepen the content of IRs and its evolution over time, a content analysis of the strategy and strategic planning disclosures was conducted based on the framework proposed by Sukhari and De Villiers (2018). The results of this content analysis were integrated with the evidence from the interviews with managers involved in the IR implementation process and disclosures.

Integrated reporting was introduced in Terna in 2011, and in the same year, the organisation entered the Business Network Pilot Program of the IIRC. It was the CSR manager who promoted the introduction of the IR in Terna.

The past CFO of Terna explained: 'When we decided to introduce the IR, this document was not particularly widespread within organisations, not sufficiently embedded in the organisational culture, and therefore, it took some time to introduce it. In addition, the need for non-financial disclosure was not well understood, especially in our context, because many 
organisations didn't need to use the IR as a market and marketing tool. At the same time, the stock market was not sufficiently prepared for it. However, in Terna, the situation was different because it was exposed to sustainability investors who asked for this document.'

During the first two years of adoption, the IRs from 2011 and 2012 showed different limitations since they were only published online on Terna's website (it was called the 'IR project') and did not represent a stand-alone report but rather a collage of information from the Sustainability Report and the Annual Report. Specifically, for these years, the IR online project was characterised by a welcome page with an explanation of Terna's 2011 IR and by linked pages that provided the contents of both the Annual Report and the Sustainability Report.

Over the years, due to the significant efforts of the CSR manager, with the support of Terna's past CFO, the IR's relevance increased. The IR was included in the Management Report, which was a section of the Annual Report, for the years 2013 and 2014. Since 2015, the IR gained relevance because the Management Report was renamed as 'Management Report - Integrated Report' within the Annual Reports. This process of change was also relevant to the IR disclosures, improving the quality and connectivity of information.

The next table provides a summary of the content analysis of the different strategy items investigated in this study based on the framework proposed by Sukhari and De Villiers (2018) and the IIRC (2013a) requirements (see Table 1).

Table 1: Strategy Disclosure

\begin{tabular}{|c|c|c|c|c|c|c|c|}
\hline \multicolumn{8}{|c|}{ TERNA SPA Integrated Report } \\
\hline Strategy disclosure & $\begin{array}{c}2011 \\
\text { Project } \\
\end{array}$ & $\begin{array}{c}2012 \\
\text { Project }\end{array}$ & 2013 & 2014 & 2015 & 2016 & 2017 \\
\hline 1. Vision & $\mathrm{X}$ & $\mathrm{X}$ & $\mathrm{X}$ & $\mathrm{X}$ & $\mathrm{X}$ & $\mathrm{X}$ & $\mathrm{X}$ \\
\hline 2. Mission & $\checkmark$ & $\checkmark$ & $\checkmark$ & $\checkmark$ & $\checkmark$ & $\checkmark$ & $\checkmark$ \\
\hline 3. Values & $\mathrm{X}$ & $\mathrm{X}$ & $\mathrm{X}$ & $\mathrm{X}$ & $\mathrm{X}$ & $\S$ & $\checkmark$ \\
\hline $\begin{array}{l}\text { 4. Did the company disclose } \\
\text { strategic goals? }\end{array}$ & $\S$ & $\S$ & $\S$ & $\S$ & $\checkmark$ & $\checkmark$ & $\checkmark$ \\
\hline \multicolumn{8}{|l|}{ 5. An IR describes } \\
\hline $\begin{array}{l}\text { a) the organisation's short-, } \\
\text { medium- and long-term strategic } \\
\text { objectives }\end{array}$ & $\mathrm{X}$ & $\mathrm{X}$ & $\mathrm{X}$ & $\mathrm{X}$ & $\mathrm{X}$ & $\mathrm{X}$ & $\mathrm{X}$ \\
\hline $\begin{array}{l}\text { b) the strategies that it has in place, } \\
\text { or intends to implement, to achieve } \\
\text { these strategic objectives }\end{array}$ & $\checkmark$ & $\checkmark$ & $\checkmark$ & $\checkmark$ & $\checkmark$ & $\checkmark$ & $\checkmark$ \\
\hline $\begin{array}{l}\text { c) the resource allocation plans that } \\
\text { it has to implement its strategy }\end{array}$ & $\checkmark$ & $\checkmark$ & $\checkmark$ & $\checkmark$ & $\checkmark$ & $\checkmark$ & $\checkmark$ \\
\hline $\begin{array}{l}\text { d) how it will measure } \\
\text { achievements and target outcomes } \\
\text { for the short, medium and long } \\
\text { term }\end{array}$ & $\S$ & $\S$ & $\S$ & $\S$ & $\S$ & $\checkmark$ & $\checkmark$ \\
\hline
\end{tabular}




\begin{tabular}{|c|c|c|c|c|c|c|c|}
\hline $\begin{array}{l}\text { a) are influenced by/respond to the } \\
\text { external environment and the } \\
\text { identified risks and opportunities }\end{array}$ & $\checkmark$ & $\checkmark$ & $\checkmark$ & $\checkmark$ & $\checkmark$ & $\checkmark$ & $\checkmark$ \\
\hline $\begin{array}{l}\text { b) affect the capital and the risk } \\
\text { management arrangements related } \\
\text { to that capital }\end{array}$ & $X$ & $X$ & $\mathrm{X}$ & $X$ & $X$ & $\checkmark$ & $\checkmark$ \\
\hline \multicolumn{8}{|c|}{$\begin{array}{l}\text { 5.1.2 What differentiates the organisation to give it a competitive advantage and enable it to create } \\
\text { value, such as }\end{array}$} \\
\hline a) the role of innovation & $\checkmark$ & $\checkmark$ & $\checkmark$ & $\checkmark$ & $\checkmark$ & $\checkmark$ & $\checkmark$ \\
\hline $\begin{array}{l}\text { b) how the organisation develops } \\
\text { and exploits intellectual capital }\end{array}$ & $X$ & $X$ & $\mathrm{X}$ & $X$ & $\checkmark$ & $\checkmark$ & $\S$ \\
\hline $\begin{array}{l}\text { c) the extent to which } \\
\text { environmental and social } \\
\text { considerations have been } \\
\text { embedded in the organisation's } \\
\text { strategy to give it a competitive } \\
\text { advantage }\end{array}$ & $\checkmark$ & $\checkmark$ & $\checkmark$ & $\checkmark$ & $\checkmark$ & $\checkmark$ & $\checkmark$ \\
\hline $\begin{array}{l}\text { 5.1.3 Key features and findings of } \\
\text { stakeholder engagement used in } \\
\text { formulating its strategy and } \\
\text { resource allocation plans }\end{array}$ & $\checkmark$ & $\checkmark$ & $\checkmark$ & $\checkmark$ & $\checkmark$ & $\checkmark$ & $\checkmark$ \\
\hline
\end{tabular}

Legend: $\checkmark$ disclosed thoroughly; X not disclosed; $\S$ disclosed only partially or fragmented

Source: Own elaboration

Regarding the strategy disclosure shown in Table 1, the mission is always explained, while the vision and values are not explicitly declared. The only exception is the 2017 IR, which includes a section dedicated to company values.

In some years (from 2014 onwards), the Chairman's message briefly cites the long-term view of the organisation, but it is not linked with strategic goals.

The five-year strategic plan is generally declared, even if in a very concise manner, and for most of the years (2011-2014), it is based on the following initiatives: i) traditional activities (safety investments and the modernisation of the electricity grid); ii) non-traditional activities; and iii) improvement in margins (EBITDA), solid capital structure, and dividend policy. The strategic goals are clearly identified in a specific section of the IR in recent years (2015-2017), while they are quite fragmented or partially described in the first versions of the IR. In each year of the 2011-2017 period, there is not a clear distinction among the short-, medium- and long-term objectives.

Regarding the strategies for achieving strategic goals, it is possible to find some information elsewhere in the IR, usually not in the same section as the strategic goals; furthermore, specific details are not provided. The IRs specify the amount of capital and the resources available to achieve the strategic objectives. However, during the first years (2011-2014), the information is more fragmented in different parts of the IR, while, over time, the section on strategic goals becomes increasingly specific and detailed.

Key performance indicators (KPIs) are sought, although, especially for 20112015, it is not clear which strategic goals these targets relate to. Furthermore, there is a preponderance of financial indicators (EBIT, EBITDA, invested capital, 
financial indebtedness and cash flows). Referring to sustainability issues, the indicators are present, especially from the 2015 IR. Nevertheless, such measures have not been classified into short-, medium- and long-term KPIs. Regarding risk management, a separate chapter is dedicated to communication and risk assessment (from 2013 onwards). The main risks in which the company might be involved, the main solutions, the opportunities and the necessary checks are identified; however, these risks are not discussed in the context of the strategic objectives and the BM. The clear identification of key risk indicators is lacking. Furthermore, how risks could affect capital is never specified, with the exception of the 2016 and 2017 IRs, which present a schematisation of six capitals and the main risks.

Referring to the impact of innovation, a special section about new and innovative solutions is often present. Great emphasis is also placed on research and training, which are essential elements for innovation.

Intellectual property is not mentioned until the $2015 \mathrm{IR}$, which dedicates an entire section to this subject. Additionally, in 2016, a good level of disclosure is present, while in the 2017 IR, the intellectual property information is very general and fragmented. Terna dedicates ample space to the environmental and social impacts of its activity and to the proposed solutions. However, it must be emphasised that, because Terna operates in a regulated market, there is no specific reference to competitive advantage.

Finally, stakeholder engagement is explained within the IRs of different years, even without specific details about strategy and resource allocation plans.

From the interviews, it emerged that, despite the document still needing substantial enhancements, the 2013 IR was greatly appreciated by the investors, who were asking for integrated information in a single document with a strong emphasis on non-financial information. Indeed, financial information was shown together with the disclosures about the organisation, its context and business description, risks and opportunities, performance and strategies, as well as future developments.

However, the CSR manager noted that 'In the IR, we still need to strongly improve the design and the link between strategic objectives and performances. Currently [with the IR 2016], we are not able to communicate our strategy in a proper manner, and I bet that the situation will the same in the future.'

$\square$ As declared by the new CFO: 'In the IR 2016, more emphasis
was given to strategy disclosure, detailing numbers and
information referring to goals, targets, KPIS and businesses. In
the past, the information was more superficial and mainly
concerned the mission and some objectives.' The CSR manager
added, 'Certainly, the linkages between strategy and IR have
resulted in a more rational choice, compared to the previous
years, of which KPIs should be included in the IR. We have
improved the indicators of operating activities that are
particularly important for our business, given the impact on the
community. However, regarding the extent of the strategic
planning part, there is something more in the IR, but we could


definitely do more. But we must also bear in mind that these processes are slow.'

After analysing the strategy disclosure, the different BM items are investigated and recorded in the next table (see Table 2).

Table 2: BM Disclosure

\begin{tabular}{|c|c|c|c|c|c|c|c|}
\hline \multicolumn{8}{|c|}{ TERNA SPA Integrated Report } \\
\hline BM disclosure & \begin{tabular}{|c|}
2011 \\
project
\end{tabular} & $\begin{array}{c}2012 \\
\text { project }\end{array}$ & 2013 & 2014 & 2015 & 2016 & 2017 \\
\hline 1. Did the company disclose a BM? & $\S$ & $\S$ & $\S$ & $\S$ & $\checkmark$ & $\checkmark$ & $\checkmark$ \\
\hline \multicolumn{8}{|l|}{ 2. An IR describes the BM, including } \\
\hline \multicolumn{8}{|l|}{2.1 Inputs } \\
\hline a) Overview of the funding model & $\checkmark$ & $\checkmark$ & $\checkmark$ & $\checkmark$ & $\checkmark$ & $\checkmark$ & $\checkmark$ \\
\hline $\begin{array}{l}\text { b) Description of manufactured } \\
\text { capital }\end{array}$ & $\checkmark$ & $\checkmark$ & $\checkmark$ & $\checkmark$ & $\checkmark$ & $\checkmark$ & $\checkmark$ \\
\hline c) The importance of human capital & $\checkmark$ & $\checkmark$ & $\checkmark$ & $\checkmark$ & $\checkmark$ & $\checkmark$ & $\checkmark$ \\
\hline $\begin{array}{l}\text { d) Value creation via intellectual } \\
\text { property }\end{array}$ & $\mathrm{X}$ & $\mathrm{X}$ & $\mathrm{X}$ & $\mathrm{X}$ & $\checkmark$ & $\checkmark$ & $\S$ \\
\hline e) Natural capital & $\mathbf{X}$ & $\mathbf{X}$ & $\mathbf{X}$ & $\mathbf{X}$ & $\checkmark$ & $\checkmark$ & $\S$ \\
\hline $\begin{array}{l}\text { f) Environmental remediation } \\
\text { efforts }\end{array}$ & $\checkmark$ & $\checkmark$ & $\checkmark$ & $\checkmark$ & $\checkmark$ & $\checkmark$ & $\checkmark$ \\
\hline g) Social and relationship capital & $\checkmark$ & $\checkmark$ & $\checkmark$ & $\checkmark$ & $\checkmark$ & $\checkmark$ & $\checkmark$ \\
\hline \multicolumn{8}{|l|}{ 2.2 Business activities and model } \\
\hline $\begin{array}{l}\text { a) Contribution of } \\
\text { effective/efficiency initiatives }\end{array}$ & $\mathrm{X}$ & $\mathrm{X}$ & $\mathrm{X}$ & $\mathrm{X}$ & $\mathrm{X}$ & $\mathrm{X}$ & $\mathrm{X}$ \\
\hline b) Market differentiation & $\mathrm{X}$ & $\mathrm{X}$ & $\checkmark$ & $\checkmark$ & $\checkmark$ & $\checkmark$ & $\checkmark$ \\
\hline $\begin{array}{l}\text { c) Reliance revenue after the initial } \\
\text { sale }\end{array}$ & $\mathrm{X}$ & $\mathrm{X}$ & $\mathrm{X}$ & $\S$ & $\S$ & $\S$ & $\S$ \\
\hline $\begin{array}{l}\text { d) Encouraging a culture of } \\
\text { innovation }\end{array}$ & $\S$ & $\S$ & $\S$ & $\checkmark$ & $\checkmark$ & $\checkmark$ & $\checkmark$ \\
\hline $\begin{array}{l}\text { e) Adaptability of the business } \\
\text { model }\end{array}$ & $\mathrm{X}$ & $\mathrm{X}$ & $\mathrm{X}$ & $\mathrm{X}$ & $\mathrm{X}$ & $\mathrm{X}$ & $\mathrm{X}$ \\
\hline \multicolumn{8}{|l|}{2.3 Outputs } \\
\hline $\begin{array}{l}\text { a) Products/services and waste/by- } \\
\text { products }\end{array}$ & $\checkmark$ & $\checkmark$ & $\checkmark$ & $\checkmark$ & $\checkmark$ & $\checkmark$ & $\checkmark$ \\
\hline \multicolumn{8}{|l|}{2.4 Outcomes } \\
\hline $\begin{array}{l}\text { a) Outcomes from activities, } \\
\text { outputs and effects on capital }\end{array}$ & $\checkmark$ & $\checkmark$ & $\checkmark$ & $\checkmark$ & $\checkmark$ & $\checkmark$ & $\checkmark$ \\
\hline \multicolumn{8}{|c|}{ 2.5 Enhancing effectiveness and readability } \\
\hline $\begin{array}{l}\text { a) Key elements of the business } \\
\text { model }\end{array}$ & $\checkmark$ & $\checkmark$ & $\checkmark$ & $\checkmark$ & $\checkmark$ & $\checkmark$ & $\checkmark$ \\
\hline $\begin{array}{l}\text { b) Diagram of key elements of the } \\
\text { BM, supported by a clear } \\
\text { explanation of these elements }\end{array}$ & $X$ & $\mathrm{X}$ & $\mathrm{X}$ & $\mathrm{X}$ & $\mathrm{X}$ & $\S$ & $\S$ \\
\hline $\begin{array}{l}\text { c) Narrative of all material matters } \\
\text { given the organisation's } \\
\text { circumstances }\end{array}$ & $\mathrm{X}$ & $\mathrm{X}$ & $\S$ & $\S$ & $\checkmark$ & $\checkmark$ & $\checkmark$ \\
\hline
\end{tabular}




\begin{tabular}{|l|c|c|c|c|c|c|c|}
\begin{tabular}{|l|l|l|l|} 
d) Key stakeholders and other \\
dependencies, key value drivers \\
and important external factors
\end{tabular} & $\S$ & $\S$ & $\S$ & $\S$ & $\S$ & $\checkmark$ & $\checkmark$ \\
\hline e) Value chain position & X & X & X & X & X & $\checkmark$ & $\checkmark$ \\
\hline f) Connection to other aspects of reporting, including \\
\hline Opportunities, risks & $\checkmark$ & $\checkmark$ & $\checkmark$ & $\checkmark$ & $\checkmark$ & $\checkmark$ & $\checkmark$ \\
\hline KPIs & $\checkmark$ & $\checkmark$ & $\checkmark$ & $\checkmark$ & $\checkmark$ & $\checkmark$ & $\checkmark$ \\
\hline Financial considerations & $\checkmark$ & $\checkmark$ & $\checkmark$ & $\checkmark$ & $\checkmark$ & $\checkmark$ & $\checkmark$ \\
\hline
\end{tabular}

Legend: $\checkmark$ disclosed thoroughly; X not disclosed; § disclosed only partially or fragmented

Source: Own elaboration

Moving the analysis to the BM disclosure, it must be said that the BM of Terna is mentioned every year, although with different degrees of detail. Indeed, beginning in 2013, the link with the value creation path began to be declared. In 2011 and 2012 , the $\mathrm{BM}$ is mentioned a few times with a vague representation of the main constituent elements just to be aligned to IIRC requirements, but in 2013, the BM is explained with greater specificity, including detailed descriptions of its key elements.

Regarding the six capitals, the funding model is always evident, as is the disclosure of manufactured capital. Great emphasis is placed on human capital, especially in terms of resources, salaries, training, generational turnover and equal opportunities. The 2016 and 2017 IRs are even unbalanced in favour of this capital.

Intellectual and natural capital are thoroughly disclosed only in 2015 and 2016, while in 2017, the disclosure is more superficial. In referring to the safeguarding the environment, the IRs pay great attention to the reduction of emissions. Social and relational capital are always disclosed, although more explicitly and exhaustively from 2013 onwards.

Regarding business activities, the contribution to the long-term BM success of initiatives that influence effectiveness and efficiency is not clearly disclosed.

Furthermore, although Terna operates in a regulated market, it provides a detailed description of the service differentiation, mainly addressing international activities. Even if the revenue generation after the initial point of sale is not clearly disclosed, it can be deduced from the information provided in the IRs published in the last few years and, in particular, since the 2015 IR.

The culture of innovation is well explicated, especially in the 2014 IR, while the ability of the BM to adapt to changes was not disclosed in any year.

Terna's services and the outcomes are disclosed in detail, although effects on the capitals are not always clear (especially before the 2015 IR).

Finally, referring to effectiveness and readability, the elements of the BM were clearly identified, although from 2011 to 2013 the descriptions were more general and did not use a diagram to identify the BM elements. The 2016 and 2017 IRs include a diagram, but it does not offer clear descriptions of the linkages among the $\mathrm{BM}$ elements. It is possible to observe a more adequate and logical narrative in the 2015 IR since the previous narrative lacked details related to specific information.

Key stakeholders are always described, although without detailed descriptions of their interactions. However, key value drivers and external factors are present only in the 2016 and 2017 IRs, as is the value chain positioning. 
Risks and opportunities are explained in each IR, as are KPIs and financial considerations; however, the link with the strategy and BM elements is almost entirely missing from all of the reports.

Terna's past CFO explained that the most significant improvements in IR disclosures have occurred since 2015; however, this process is still incomplete: 'In past years, the strategy and BM disclosure were poor and superficial, while starting from this year, some progress has been achieved. But to be honest, strategic planning has not yet received adequate weight, and there are still insufficient links with evaluation and rewarding tools.'

The CSR manager, in a recent interview, also specified that 'The unexpected change of the strategic planning manager at the beginning of 2018 has partially slowed this process of improvements of BM disclosure within the IR. In the last published IR [2017], we worked to improve both the layout and the contents. In fact, the report is organised differently, adopting a horizontal approach based on different business areas, more in line with the connectivity of information required by the IIRC. Of course, this new version has affected strategy disclosure, even if without significant steps forward compared to 2016 in terms of integration among strategy, BM and KPIs.'

Finally, the link between the strategic goals and BM items is analysed and summarised in the next table (see Table 3 ).

Table 3: Strategy-BM Link

\begin{tabular}{|l|c|c|c|c|c|c|c|}
\hline \multicolumn{7}{|c|}{ TERNA SPA } \\
\hline & $\begin{array}{c}\mathbf{2 0 1 1} \\
\text { project }\end{array}$ & $\begin{array}{c}\mathbf{2 0 1 2} \\
\text { project }\end{array}$ & $\mathbf{2 0 1 3}$ & $\mathbf{2 0 1 4}$ & $\mathbf{2 0 1 5}$ & $\mathbf{2 0 1 6}$ & $\mathbf{2 0 1 7}$ \\
\hline Number of strategic goals disclosed & 6 & 5 & 5 & 3 & 6 & 4 & 3 \\
\hline $\begin{array}{l}\text { Number of strategic goals linked to } \\
\text { the BM }\end{array}$ & 0 & 0 & 0 & 0 & 0 & 0 & 0 \\
\hline Percentage of strategic goals linked & $0 \%$ & $0 \%$ & $0 \%$ & $0 \%$ & $0 \%$ & $0 \%$ & $0 \%$ \\
\hline
\end{tabular}

Legend: $\checkmark$ disclosed thoroughly; X not disclosed; $\S$ disclosed only partially or fragmented

Source: Own elaboration

Table 3 reveals that the link between strategic goals and the BM elements is currently not clearly explicated. Referring to the 2011 to 2014 IRs, strategic goals are not clearly defined and grouped within a specific section or linked to BM elements. In the 2016 and 2017 IRs, the BM refers only to general objectives (e.g., efficiency, sustainability, safety, continuity), and for those years, the direct link with the strategic goals that are identified is not evident.

The past Strategic Planning manager explained that the BSC can be considered the most significant tool for describing the BM and the value creation path, which are key elements of integrated reporting. The same manager explicitly claimed that 'Terna was the first Italian organisation that implemented the BSC in 1999, and this tool was and is considered a significant means for organisational change and learning. The BSC is strictly connected with the business plan, in terms of time horizon, is integrated with the enterprise risk management and partially also with 
the $M B O$, as the first managerial lines are partly accountable to BSC goals. Currently, we are one of the few organisations that use the BSC in a pervasive way, with a structured process but not yet within the IR.'

The Human Resources manager clarified that the integration between the KPIs included in the BSC and the KPIs disclosed in the IR is still not complete. However, over the years, some progress has been achieved: managers are empowered on a greater number of indicators published within the IR, while in the past, the KPIs included in the BSC and assigned to managers did not coincide with those included in the IR.

The past Strategic Planning manager also explained that the BSC can offer significant support in the preparation of the IR, and at the same time, integrated reporting can help to achieve integrated planning. However, the IR is still not fully aligned with the BSC content because the organisation is still not ready to communicate sensitive information to the market. As affirmed by the current Strategic Planning manager, 'If you want to read the strategic disclosure, the IR is not currently the proper document. Reading this report, you can get a general idea of the future direction of the organisation, but you cannot think you really understand the cause and effect links between the different strategic variables. And it is right that it is so! This is strategic and delicate information that must be kept inside the organisation, within, for example, our BSC.'

Finally, the Investor Relations manager declared that the company has periodically attempted to understand whether there is some useful information for investors and analysts that could be included within the IR: 'It is not unusual for us to ask institutional investors for opinions and suggestions on IR.' The Investor Relations manager also claimed that 'We have now [2017 IR] reached a good level of integration, even if not fully in line with the industrial plan. This improvement has been partially driven by investors and analysts since they influenced the information content of the IR. I'm sure that they will become increasingly relevant in the future since the requests of investors will drive the evolution of this tool.'

In conclusion, from 2011 to 2017, there was gradual improvement in the structure and content of the IRs published by Terna, with better results in terms of information quality and connectivity. However, there is still no evidence of the cause and effect relationships among the strategic initiatives, critical success factors and $\mathrm{BM}$ element performance indicators.

\section{Analysis and Discussion}

The findings presented in the previous section show the process of the implementation and improvement of integrated reporting within Terna. In line with Argento et al. (2019), the process of introducing the Integrated Report was not easy because there were many cultural challenges to face and some tensions to overcome. In particular, from the interviews, it emerged that, in the beginning, the introduction of the Integrated Report was strongly desired by the CSR manager, while the Finance area showed a certain reluctance to include strategic and operative non-financial information, such as environmental, social and corporate governance indicators, in the Annual Report. At the beginning, therefore, non- 
financial disclosure was not completely accepted, although a significant impulse to do so came from the financial market urging the adoption of integrated reporting.

Consequently, the 2011 and 2012 IRs were only published online to avoid altering the Annual Report. For these years, no clear links were provided among the different sections of the IR, in part because the IR disclosures were based on crossreferences to information published within the Annual Report and Sustainability Report. The strategy and BM disclosure were poorly described and contained little detail. Only in 2013, due in part to the commitment of the Finance area, did the IR become part of the Management Report. However, despite the improvements in the connectivity of information, the resulting BM disclosure was still fragmented, did not use a diagram and was mainly characterised by a description of the business and external context, rather than inputs, activities, outputs and outcomes. Links between the BM elements and the other sections of the IR, such as strategic goals, risks and performances, were lacking.

The 2014 IR structure and contents remained almost unchanged compared with those of the previous year, also due to internal tensions between CSR and the Finance area.

However, with the 2015 IR, it was possible to take a substantial step forward: the IR started to show a distinct structure, and it was no longer the copying and pasting of information from the Sustainability Report and Annual Report. Therefore, Terna's business and organisation, strategic plans, goals, the six capitals, risks and performance could be better understood.

As explained by the CSR and finance managers, the preparation of the 2015 IR implied a strong change at the organisational level: functional areas had started to collaborate and communicate with each other, embracing a process vision with the aim of contributing to the preparation of the IR. The CSR manager, in strong synergy with the $\mathrm{CFO}$ and Finance managers, played a key role in coordinating the different actors involved. As observed by the current CFO, 'IR was the engine for an inter-functional and transversal approach.'

Unfortunately, the non-financial information provided in the 2015 IR was not strongly related to the BM, which is internally defined by means of strategic planning and management accounting tools adopted by the company (Cinquini \& Tenucci, 2011; Zott et al., 2011). In fact, the CSR and the Strategic Planning managers confirmed that the 2015 IR was still far from communicating the path towards the achievement of the identified strategic goals, remaining a document designated for external disclosures.

The new CFO claimed that, in the 2016 IR, there was a stronger emphasis on strategic planning, goals, targets, KPIs and businesses. The current CFO also said, 'For the IR 2016, I can tell you that an important member of the Board of Directors congratulated us for the work done, saying that the IR will be used as the main document to present the company.'

In this report, a stronger link emerged between the BM of the company and the BSC, especially compared to the IRs of previous years. However, through a deeper analysis, it emerges that this link is limited to sustainability issues.

The 2017 IR changed the way in which contents are disclosed, adopting a transversal approach more oriented towards processes but without substantial changes in terms of links between strategy and BM disclosures. In contrast, the 
transversal approach in some cases (e.g., for intellectual property and natural capital disclosures) created greater fragmentation, with greater difficulties in contextualising inputs within the BM.

Over the years, an improvement in the readability, connectivity and robustness of information is evident, due in part to the more detailed guidelines issued by the IIRC. From 2011 to 2017, growing attention was paid to strategic information. As explained by the CSR manager and confirmed by the past and current CFO managers, the IR process is constantly evolving to guarantee growing improvement. Indeed, the IR of the last three years has been further improved in terms of a better balance in content, a greater depth of strategic planning disclosures, and synthesis.

In line with Cheng et al. (2014), currently it seems that information is limited to the most important requests coming from the financial market. Although attention is increasingly paid to strategic information, the disclosure of the key factors that are truly measured by the BSC to describe the BM and the value creation path is lacking. Indeed, Terna is still far from disclosing the cause and effect relationships among strategic intentions, strategic initiatives, critical success factors and KPIs (Cinquini \& Tenucci, 2011). Specifically, the company is currently unable to emphasise the links between strategic goals and the BM because it does not provide an exhaustive description of the strategic goals and BM elements. A deficiency in the disclosure of the organisation's vision and values was also observed, which is only hinted at in the Chairman's letter (Stent \& Dowler, 2015).

According to the evidence of Ernst and Young (2014) and Sukhari and De Villiers (2018), the research shows that the company does not disclose performance measures or the risks that can be specifically traced to strategic goals.

Additionally, the findings show that the IRs of the last few years have been remarkably appreciated by investors and analysts, and this aspect is very delicate for a listed company because it influences the trend of its stock quotation. In this way, as confirmed by the Investor Relations manager, it seems that investors and analysts can influence which types of information are provided in the IR, confirming the first critique emphasised by Cheng et al. (2014) that providers of financial capital are prioritised over other stakeholders. Therefore there is no systematic description of the BM and of the organisation's real strategic intentions. In this regard, Melloni et al. (2016) observed that BM disclosure included within the IR may be subjected to impression management strategies, and this is particularly evident when managers try to be compliant with the expectations of the organisation's audience (i.e., investors').

In conclusion, as the past Strategic Planning manager affirmed, Terna is currently unable - or does not feel the need - to completely communicate its strategy map and its BM to the market, consolidating the BSC into the IR, essentially because the organisation did not want to disclose sensitive information to the market. The IR is still far from being considered a management tool. As the current Strategic Planning manager explained, the IR is not the proper document to read and understand the strategy; rather, the BSC is. 


\section{Conclusions}

In an attempt to fill the literature gaps on the change processes and disclosures related to IRs (Cheng et al., 2014; De Villiers et al., 2014; Stubbs \& Higgings, 2014; Sukhari \& De Villiers, 2018), the purpose of this paper was to explore the extent to which strategies and the BM are disclosed in the IR. The study focused on Terna, which has recently implemented integrated reporting but has long used the $\mathrm{BSC}$ as a managerial tool, attempting to understand the reasons for the changes in the IR disclosures over the time frame of 2011-2017. A content analysis based on the framework proposed by Sukhari and De Villiers (2018) and the IIRC framework was executed to measure the quality of the IR disclosures related to Terna's strategy and BM. Three strategy disclosures still fall short. First, a clear explication of the organisation's vision is lacking within the IR. Second the strategic goals are mentioned without a clear differentiation between the shortmedium and long term. Third, how such goals are measured and linked with the $\mathrm{BM}$ is not clearly indicated. Additionally, how the organisation develops and exploits intellectual capital is not clearly explained. Regarding BM disclosures, there is a lack of information about value creation through intellectual property, the BM's contribution to the success of initiatives that influence the effectiveness and efficiency of business activities, and the main BM elements. Another important element that organisations do not currently disclose is the BM's adaptability to changes.

Considering the findings obtained through the analytical reading of the various IRs published from 2011 to 2017, complemented with the interviews, it can be seen how efforts have been undertaken to integrate the financial information with the non-financial information thanks to synergistic cooperation among different business areas, particularly the CSR area with the Finance area. The non-financial information presented in the IR was initially the same information published in the Sustainability Report, and only later did the organisation rethink the type of communication it provided to the market, focusing on the needs of the financial market (Argento et al., 2019). This change entailed an organisational and cultural change that led the organisation to improve its boundary-crossing approach to business processes.

This study unveils the effects of the voluntary adoption of IR. On the one hand, the preparation and publication of the IR represent a method for deeper disclosures of non-financial information for different stakeholders (Topazio, 2013), even if particular attention is paid to the requirements of investors and analysts. On the other hand, the implementation and development of integrated reporting have not yet implied a real link between strategy disclosures and the BM, consolidating the BSC elements by which managers are empowered and evaluated (Cinquini \& Tenucci, 2011). Some doubts about the possibility of achieving such a link through the preparation of an IR remain (see also Melloni et al., 2016).

The changes in the disclosures, in addition to being strongly promoted by the CSR manager, partially reflect the information needs expressed by the market, although these changes do not mean that there is full transparency in the disclosures provided externally about the BM and the related linkages. 
This paper unveils how the willingness to protect sensitive information dominates. The time is still not ripe for organisations to reveal all of their BSC, which, for reasons of confidentiality, is still used as an instrument for internal communication and accountability. In addition, this paper shows that a change in key managerial positions hinders the process of full disclosure.

This paper adds value to the recent literature on integrated reporting (De Villiers et al., 2014; De Villers et al., 2016; Dumay et al., 2016; Stubbs \& Higgings, 2014) and above all on the integration of strategy and BM disclosures (Sukhari \& De Villiers, 2018). In particular, this paper explores the extent to which the strategy and $\mathrm{BM}$ of an organisation are truly communicated to the market through IRs. This study shows that, even if the strategy and BM are not completely revealed in the IR, significant improvements in the IRs, in terms of their readability and the quality of information they provide, can be made when the efforts of internal actors are complemented by the requests of analysts and investors. However, the real challenge for organisations is to grasp the opportunity to grow towards a more responsible vision of their own businesses when preparing the IR.

The research also provides insights into how strategy disclosures have improved over the years, although there continue to be shortcomings. This research would be of interest to organisational managers as well as investors. Specifically, organisations could benefit from reconsidering how they amend BM disclosures to align with their strategic goals, KPIs and risks. At the same time, better disclosures ensure that investors have access to all relevant information, benefitting their decision-making processes.

This study presents the results stemming from a single case study, making generalisation difficult, and despite the interviews conducted to complement the findings of the content analysis, reliability and validity issues are inevitable.

\section{Bibliography}

Amit, R., \& Zott, C. (2001). Value Creation in E-Business. Strategic Management Journal, 22(6-7), 493-520. http://dx.doi.org/10.1002/smj.187

Amit, R., \& Zott, C. (2010). Business Model Innovation: Creating Value in Times of Change. IESE Business School, University of Navarra working paper. Retrieved from http://media.iese.edu/research/pdfs/DI-0870-E.pdf (accessed on 6 December 2018).

Argento, D., Culasso, F., \& Truant, E. (2019). From Sustainability to Integrated Reporting: The Legitimizing Role of the CSR Manager. Organization \& Environment, 32(4), 484-507.

http://dx.doi.org/10.1177/1086026618769487

Beattie, V., McInnes, B., \& Fearney, S. (2004). A Methodology for Analysing and Evaluating Narratives in Annual Reports: A Comprehensive Descriptive Profile and Metrics for Disclosure Quality Attributes. Accounting Forum, 28(3), 205-236.

http://dx.doi.org/10.1016/j.accfor.2004.07.001

Brondoni S. M. (2003). Network Culture, Performance \& Corporate Responsibility. Symphonya. Emerging Issues in Management (symphonya.unimib.it), (1), 8-24.

http://dx.doi.org/10.4468/2003.1.02brondoni 
Brondoni, S. M. (2014). Global Capitalism and Sustainable Growth: From Global Products to Network Globalisation, Symphonya. Emerging Issues in Management (symphonya.unimib.it), (1), 10-31.

http://dx.doi.org/10.4468/2014.1.02brondoni

Brondoni, S. M., \& Bosetti, L. (2018). Ouverture de 'Integrated CSR Management', Symphonya. Emerging Issues in Management (symphonya.unimib.it), (1), 1-17.

http://dx.doi.org/10.4468/2018.1.01ouverture

Bryman, A., \& Bell, E. (2011). Business Research Methods (3 ${ }^{\text {rd }}$ ed.). Oxford, UK: Oxford University Press.

Cantino, V., \& Cortese, D. (2017). Integrated Report System: Purposes and Benefits of the Italian Law, Symphonya. Emerging Issues in Management (symphonya.unimib.it), (1), 83-94.

http://dx.doi.org/10.4468/2017.1.07cantino.cortese

Casadesus-Masanell, R., \& Ricart, J.E. (2010). From Strategy to Business Models and into Tactics. Long Range Planning, 43(2-3), 195-215.

http://dx.doi.org/10.1016/j.lrp.2010.01.004

Chandler, A. (1962). Strategy and Structure. Cambridge, MA: M.I.T. Press.

Cheng, M., Green, W., Conradie, P., Konishi, N., \& Romi, A. (2014). The International Integrated Reporting Framework: Key Issues and Future Research Opportunities, Journal of International Financial Management \& Accounting, 25(1), 90-119.

http://dx.doi.org/10.1111/jifm.12015

Chesbrough, H., \& Rosenbloom, R.S. (2002). The Role of the Business Model in Capturing Value from Innovation: Evidence from Xerox Corporation's Technology Spin-Off Companies, Industrial and Corporate Change, 11(3), 529-555.

http://dx.doi.org/10.1093/icc/11.3.529

Cho, C.H., \& Patten, D.M. (2007). The Role of Environmental Disclosures as Tools of Legitimacy: A Research Note, Accounting, Organizations and Society, 32(7-8), 639-647.

http://dx.doi.org/10.1016/j.aos.2006.09.009

Cinquini, L., \& Tenucci, A. (2011). Business Model in Management Commentary and the Links with Management Accounting. Financial Reporting, (3 supp), 41-59.

http://dx.doi.org/10.3280/FR2011-SU003003

Cox, J. W., \& Hassard, J. (2007). Ties to the Past in Organization Research: A Comparative Analysis of Retrospective Methods. Organization, 14, 475-497.

http://dx.doi.org/10.1177/1350508407078049

De Villiers, C., Rinaldi, L., \& Unerman, J. (2014). Integrated Reporting: Insights, Gaps and an Agenda for Future Research. Accounting, Auditing \& Accountability Journal, $27(7), 1042-1067$. http://dx.doi.org/10.1108/AAAJ-06-2014-1736

De Villiers, C., Hsiao, P.C. K., \& Maroun, W. (2017). Developing a Conceptual Model of Influences Around Integrated Reporting: New Insights, and Directions for Future Research. Meditari Accountancy Research, 25(4), 450-460.

http://dx.doi.org/10.1108/MEDAR-07-2017-0183

De Villiers, C., Venter, E., \& Hsiao, P.C.K. (2016). Integrated Reporting: Background, Measurement Issues, Approaches and an Agenda for Future Research. Accounting \& Finance, 27, 1042-1067.

http://dx.doi.org/10.1111/acfi.12246

Dumay, J., Bernardi, C., Guthrie, J., \& Demartini, P. (2016). Integrated Reporting: A Structured Literature Review, Accounting Forum, 40(3), 166-185.

http://dx.doi.org/10.1016/j.accfor.2016.06.0

Du Toit, E., van Zyl, R., \& Schutte, G. (2017). Integrated Reporting by South African Companies: A Case Study. Meditari Accountancy Research, 25(4), 654-674. 
http://dx.doi.org/10.1108/MEDAR-03-2016-0052

Eisenhardt, K.M., \& Graebner, M.E. (2007). Theory Building from Cases: Opportunities and Challenges, The Academy of Management Journal, 50(1), 25-32.

http://dx.doi.org/10.5465/amj.2007.24160888

Epstein, M. J., \& Buhovac, A. R. (2014). Making Sustainability Work: Best Practices in Managing and Measuring Corporate Social, Environmental, and Economic Impacts $\left(2^{\text {nd }}\right.$ ed.), BerrettKoehler Publishers, San Francisco.

Epstein, M. J., \& Manzoni, J. F. (1997). The Balanced Scorecard and Tableau de Bord: Translating Strategy into Action, Management Accounting: Official Magazine of Institute of Management Accountants, 79(2), 28-36.

Epstein, M. J., \& Roy, M. J. (2001). Sustainability in Action: Identifying and Measuring the Key Performance Drivers. Long Range Planning, 34(5), 585-604.

http://dx.doi.org/10.1016/S0024-6301(01)00084-X

Ernst \& Young. (2014). EY's Excellence in Integrated Reporting Awards 2014. Retrieved from: http://integratedreporting.org/resource/eys-excellence-in-integrated-reporting-awards-2014/ (accessed on 5 February 2019).

Grant, R.M. (2016). Contemporary Strategy Analysis: Text and Cases ( $9^{\text {th }}$ ed.), John Wiley \& Sons, Chichester.

Guthrie, J., Petty, R., Yongvanich, K., \& Ricceri, F. (2004). Using Content Analysis as a Research Method to Inquire into Intellectual Capital Reporting, Journal of Intellectual Capital, 5(2), 282293.

http://dx.doi.org/10.1108/14691930410533704

Haji, A., \& Anifowose, M. (2016). The trend of integrated reporting practice in South Africa: Ceremonial or substantive? Sustainability Accounting, Management and Policy Journal, 7(2), 190-224.

http://dx.doi.org/10.1108/SAMPJ-11-2015-0106

IIRC. (2013a). The International Integrated Reporting Framework, International Integrated Reporting Council. Retrieved from: http://integratedreporting.org/wp-content/uploads/2013/12/1312-08-THE-INTERNATIONAL-IR-FRAMEWORK-2-1.pdf (accessed on 7 January 2019).

IIRC. (2013b). Business Model: Background Paper for Integrated Reporting, issued by the Technical Collaboration Group of the IIRC, International Integrated Reporting Council. Retrieved from: http://integratedreporting.org/wp-content/uploads/2013/03/Business_Model.pdf (accessed on 21 January 2019).

Kaplan, R., \& Norton, D. (1992). The Balanced Scorecard: The Measures that Drive Performance. Harvard Business Review, 70(1), 71-79.

Lambert, S. (2008). A Conceptual Framework for Business Model Research. Bled 2008 Conference Proceedings, 24. Retrieved from: https://aisel.aisnet.org/bled2008/24 (accessed on 4 February 2019).

Lev, B. (2001). Intangibles: Measurement, Management and Reporting, Brookings Institution, Washington DC.

Melloni, G., Stacchezzini, R \& Lai, A. (2016). The Tone of Business Model Disclosure: An Impression Management Analysis of the Integrated Reports, Journal of Management and Governance, 20(2), 295-320. http://dx.doi.org/10.1007/s10997-015-9319-z

Milne, P. (2007). Motivation, Incentives and Organisational Culture, Journal of Knowledge Management, 11(6), 28-38.

http://dx.doi.org/10.1108/13673270710832145

Mosca, F. \& Civera, C. (2017). The Evolution of CSR: An Integrated Approach. Symphonya. Emerging Issues in Management (symphonya.unimib.it), (1), 16-35.

http://dx.doi.org/10.4468/2017.1.03mosca.civera 
Nielsen, C., \& Bukh, P.N. (2011). What Constitutes a Business Model: The Perception of Financial Analysts. International Journal of Learning and Intellectual Capital, 8(3), 256-271.

http://dx.doi.org/10.1504/IJLIC.2011.041072

Osterwalder, A. (2004). The Business Model Ontology: A Proposition in a Design Science Approach, Ph.D. Dissertation, University of Lausanne, Lausanne, Switzerland. Retrieved from http://www.hec.unil.ch/aosterwa/PhD/Osterwalder_PhD_BM_Ontology.pdf (accessed on 8 January 2019).

Osterwalder, A., \& Pigneur, Y. (2010). Business Model Generation: A Handbook for Visionaries, Game Changers, and Challengers, Hoboken, NJ: John Wiley \& Sons.

RobecoSAM. (2018). RobecoSAM yearbook, 2018. Retrieved from https://yearbook.robecosam.com (accessed on 15 November 2018).

Ryan, B., Scapens, R.W., \& Theobald, M. (2002). Research Method and Methodology in Finance and Accounting ( $2^{\text {nd }}$ ed.), Cengage Learning, London.

Salvioni D.M., \& Bosetti L. (2014). Sustainable Development and Corporate Communication in Global Markets, Symphonya. Emerging Issues in Management (symphonya.unimib.it), (1), 32-51. http://dx.doi.org/10.4468/2014.1.03salvioni.bosetti

Schaltegger, S., Lüdeke-Freund, F., \& Hansen, E.G. (2012). Business Cases for Sustainability: The Role of Business Model Innovation for Corporate Sustainability, International Journal of Innovation and Sustainable Development, 6(2), 95-119.

http://dx.doi.org/10.1504/IJISD.2012.046944

Stent, W., \& Dowler, T. (2015). Early Assessments of the Gap between Integrated Reporting and Current Corporate Reporting, Meditari Accountancy Research, 23(1), 92-117. http://dx.doi.org/10.1108/MEDAR-02-2014-0026

Stubbs, W., \& Higgins, C. (2014). Integrated Reporting and Internal Mechanisms of Change, Accounting, Auditing \& Accountability Journal, 27(7), 1068-1089

http://dx.doi.org/10.1108/AAAJ-03-2013-1279

Sukhari, A., \& De Villiers, C. (2018). The Influence of Integrated Reporting on Business Model and Strategy Disclosures. Australian Accounting Review, forthcoming.

http://dx.doi.org/10.1111/auar.12264

Teece, D.J. (2010). Business Models, Business Strategy and Innovation. Long Range Planning, 43(2-3), 172-194.

http://dx.doi.org/10.1016/j.lrp.2009.07.003

Terna (2018). Annual Report 2017. Retrieved from: http://www.terna.it/en$\mathrm{gb} /$ investorrelations/bilancierelazioni.aspx (accessed on 13 November 2018)

Topazio, N. (2013). Consultation Draft of the International $<$ IR $>$ Framework, Chartered Institute of Management Accountants. Retrieved from: http://integratedreporting.org/wpcontent/uploads/2013/08/180_CIMA1.pdf (accessed on 4 February 2019).

Unerman, J. (2000). Methodological Issues: Reflections on Quantification in Corporate Social Reporting Content Analysis, Accounting, Auditing and Accountability Journal, 13(5), 667-680. http://dx.doi.org/10.1108/09513570010353756

Weber, R.P. (1990). Basic Content Analysis: Quantitative Applications in the Social Sciences $\left(2^{\text {nd }}\right.$ ed $)$, Sage University Paper Series, Newbury Park.

Yin, R.K. (1994). Case Study Research: Design and Methods (2 $2^{\text {nd }}$ ed.), Sage, London.

Zambon, S. (2011). The Managerialisation of Financial Reporting: An Introduction to a Destabilising Accounting Change, Financial Reporting, (3 supp.), 5-16.

http://dx.doi.org/10.3280/FR2011-SU003001

Zott, C., Amit, R., \& Massa, L. (2011). The Business Model: Recent Developments and Future Research, Journal of Management, 37(4), 1019-1042.

http://dx.doi.org/10.1177/0149206311406265 